\title{
Application of Artificial Intelligence Techniques in Operating Mode of Professors' Academic Governance in American Research Universities
}

\author{
Ruishu Wang $\left(\mathbb{D},{ }^{1,2}\right.$ Jiannan Li $\mathbb{D}^{3},{ }^{3}$ Wanbing Shi $\mathbb{D},{ }^{4}$ and Xin $\mathrm{Li} \mathbb{D}^{2}$ \\ ${ }^{1}$ School of Humanities and Law, Northeastern University, Shenyang, Liaoning 110169, China \\ ${ }^{2}$ Foreign Studies College, Northeastern University, Shenyang, Liaoning 110819, China \\ ${ }^{3}$ International Cooperation and Exchange Department, Northeastern University, Shenyang, Liaoning 110819, China \\ ${ }^{4}$ Special Education Research Center, Nanjing Normal University of Special Education, Nanjing, Jiangsu 210038, China
}

Correspondence should be addressed to Wanbing Shi; sennanjing0802@163.com and Xin Li; fscfsc0802@163.com

Received 22 October 2021; Revised 4 November 2021; Accepted 9 November 2021; Published 18 November 2021

Academic Editor: Narasimhan Venkateswaran

Copyright (C) 2021 Ruishu Wang et al. This is an open access article distributed under the Creative Commons Attribution License, which permits unrestricted use, distribution, and reproduction in any medium, provided the original work is properly cited.

Artificial intelligence technology is an important transformative force for teaching innovation in the intelligent era. It is being widely used in American school teaching, including the design of intelligent tutoring systems to achieve precise problem solving, the machine learning technology to ensure personalized activity design, the creation of intelligent virtual reality to promote classroom teaching contextualization, and the development of intelligent evaluation systems to ensure the scientific evaluation of capabilities. In the process of advancing the teaching and application of artificial intelligence technology, the United States has built a linkage mechanism of federal leadership, university follow-up, and social collaboration and implemented the smart technology in school teaching and professors' academic governance. This paper is aimed at studying the professors' academic governance of American research universities by Internet data mining, historical analysis method, documentary method, survey method, and other methods. Professors' academic governance is a vital part of the modern university system that causes the institutional reform of the internal governance structure of modern universities. The United States is a powerful country in higher education, and professors in American research universities have always participated in university academic governance for centuries. By studying the definition, history, and development and mode of operation of professors' academic governance in American research universities, the results indicate a clear division of power and responsibility between the professors and administrators based on an artificial intelligence decision system in American research universities. Also, there is a good communication platform based on artificial intelligence environment for professors to discuss their opinions on academic affairs. Third, professors exercise academic power under the guarantee of diversified guaranteed systems based on the artificial intelligence evaluation system and the ideology of mutual respect based on the artificial intelligence management and service system. Studying the application of artificial intelligence techniques in operating mode and enlightenment of professors' academic governance in an American research university is of great significance to promote the construction of other modern universities' professors' academic governance system.

\section{Introduction}

"Professors' academic governance" means that the university grants professors the academic power to realize the effective governance of the university's academic affairs through the democratic management of academic affairs by academic experts. The "professors' academic governance" could enhance the power of professors in the internal governance of the university and promote the administrative reform to enhance the academic autonomy of the university [1]. As an essential part of the modern university system, "professors' academic governance" is an institutional reform of modern universities' internal governance structure. It is of great significance to study the rules and path of "professors' academic governance" operation mode and management systems. The United States is a powerful country in higher 
education, and professors in American research universities have always participated in university academic governance since the colonial period. In the power structure of American research universities, the board of trustees has the final decision-making power on the university's major affairs, the administrators represented by the president have the administrative power, and the professors have the autonomy in academic governance (shown in Figure 1). This kind of governance model has led to the formation of organizational structures in American research universities characterized by decentralization, cogovernance, and mutual balance (shown in Figure 2), making the operation mode of "professors' academic governance" in American research universities extraordinarily successful. American research university professors have full academic autonomy in dealing with academic affairs, which contributes to making the best decisions conducive to teaching and scientific research. Exploring the effective modes of "professors' academic governance" in American research universities and giving full play to professors' roles in academic research, academic affairs, and university management have enlightened effects on improving the modern university system and governance structure. Therefore, it has theoretical value and practical significance for exploring the operating mode and experience of American research university "professors' academic governance."

\section{Methodology}

2.1. Research Object. This paper is aimed at figuring out the application of artificial intelligence techniques in operating mode and characteristics of "professors' academic governance" of American research universities based on Internet data mining with the supplement of the survey method, historical analysis method, and documentary method to promote the construction of other modern universities' "professors' academic governance" system.

2.2. Research Tools. The application of artificial intelligence techniques in operating mode of "professors' academic governance" in American research universities is the research subject of this study with an in-depth analysis. In this research, Internet data mining, survey method, documentary analysis method, and historical analysis method were utilized to fully draw on the application of artificial intelligence techniques in operating mode of "professors' academic governance" in American research universities and provide suggestions for promoting the construction of modern research universities. The documentary analysis method is the most basic and most widely used research method in education research. Researchers discover the essential attributes and inner nature of things based on the retrieval, collection, identification, sorting, reading, thinking, and analysis of documents. The connection and regularity of the facts form a method of scientific understanding of facts. Furthermore, historical analysis is one of the basic methods of academic research, as well as a specific analysis method, that is, a method of exploring objective things and social phenomena from the perspective of development and change. It specifically refers to the objective and scientific analysis of the his- torical data of the specific research object to clarify how it happened in history and how it developed into the status quo. This research mainly analyzed, connected, and compared the characteristics of "professors' academic governance" in American research universities at different stages of their scholarship and examined the different emphases on the governance of American research universities in different periods, with a view to discovering the history of their current characteristics through the study of their definition and historical background. Meanwhile, the survey method is a commonly used method in scientific research, which refers to a research method that directly obtains relevant materials through the extensive understanding of objective conditions and conducts the objective and scientific analysis of these materials. Survey methods are generally carried out in a natural and objective process and can be used in descriptive and exploratory research. This research collected related data of the application of artificial intelligence techniques in "professors' academic governance" operating mode in American research universities based on Internet data mining and survey method to draw scientific conclusions for the application of artificial intelligence techniques in operating mode of "professors' academic governance" in American research universities.

\section{Definition of Professors' Academic Governance}

Professors in "professors' academic governance" do not only refer to the group of professors but also refer to educators and researchers who have the academic ability to participate in the academic governance of universities to make their opinions be reflected in academic power. Zhang believed that the content of the "professors' academic governance" included the management of academic disciplines and teachings, such as the setting of disciplines and majors, the formulation of teaching plans, the promotion of academic staff, and the formulation of student training programs [2]. Xiong and Guo stated that "professors' academic governance" referred to professors engaging in academic activities with research attributes, including teaching and educating, scientific research, and decision-making in academic affairs [3]. Yao et al. believed that "professors' academic governance" referred to the university's philosophy and governance structure in which the faculty community with professors as the main body exercised power in academic research, academic evaluation, discipline construction, academic review, talent training, and academic decisionmaking [4]. The essence of "professors' academic governance" represents the separation of administrative power and academic power within the university. "Professors' academic governance" means that the university's internal governance institutions delegate the academic affairs to professors to implement professors' management power over academic affairs. The key to "professors' academic governance" is to properly divide academic power and administrative power, reasonably regulate the scope and procedures of their roles, divide a relatively separate field for academic power, and establish a system to exert its effects in academic 


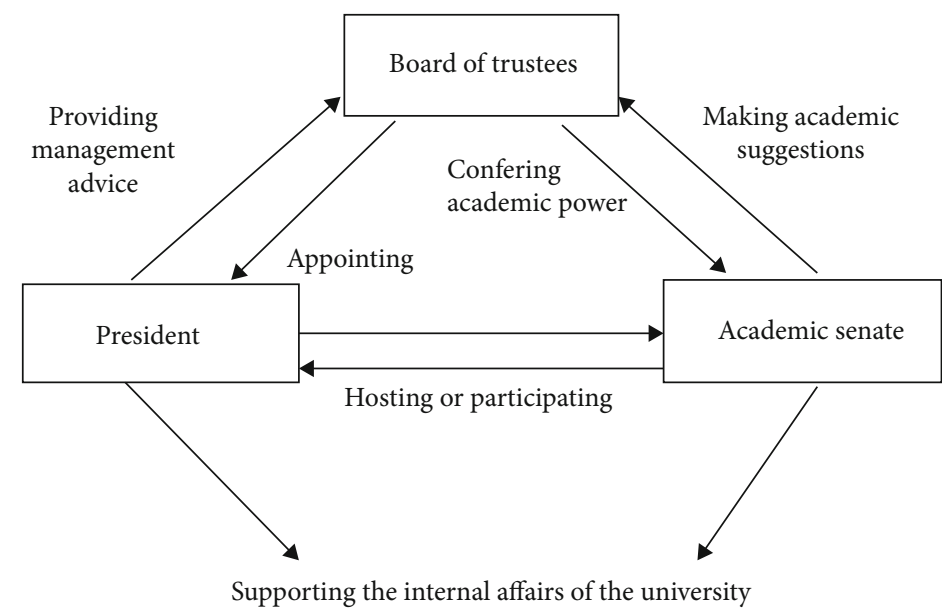

FIgURe 1: Power distribution of American research universities' internal governance structure.

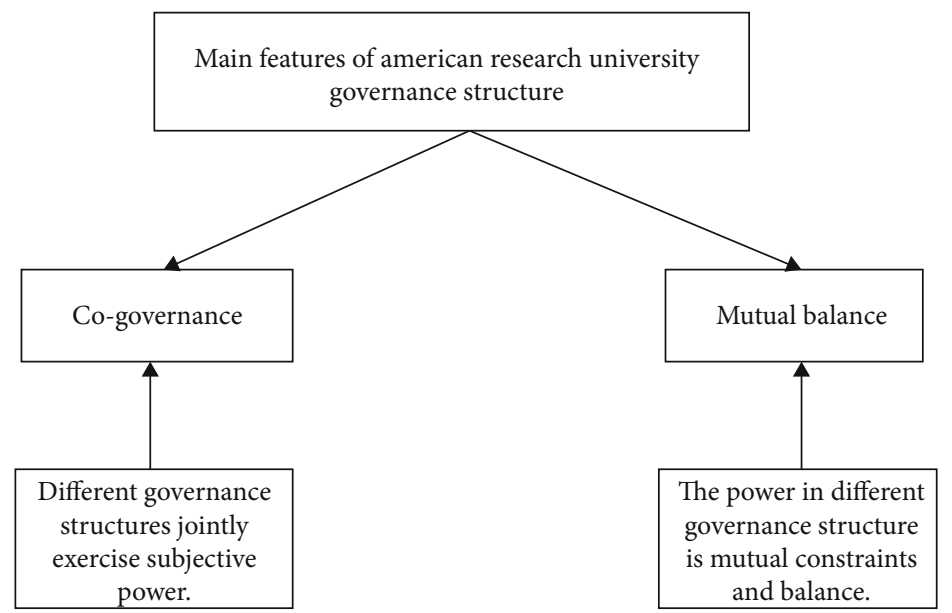

FIgURE 2: Main features of American research universities' governance structure.

management activities. The system guarantee discipline reduces the space and possibility of intersection and the chance of power conflicts. Meanwhile, "professors' academic governance" represents the balance of university power. "Professors' academic governance" effectively balances the relationship between academic power and administrative power within the organization through a clear relationship of power and responsibility and promotes collective consultation, joint participation, and mutual supervision in dealing with university affairs.

\section{History and Development of Professors' Academic Governance in American Research Universities}

The idea of "professors' academic governance" sprouted in medieval universities in Europe. When the University of Paris was founded, it established a "teacher organization" where teachers were responsible for managing the university's internal affairs, undertaking decision-making execution, and supervision tasks. Professors maintained their right to manage students and collectively managed the entire university. With the influence of the Renaissance, European universities entered a new era. During this period, the "professors' academic governance" was further improved in Europe. Professors had the right to express their ideas and vote in the university's management and the right to develop new academic activities. During the colonial college period, American universities have already formed the mode of constructing a board of trustees of laymen to manage the university. Therefore, the influence of teachers in university management was feeble [5]. After the Civil War, the idea of European university governance gradually entered the United States. With the establishment of the American Association of University Professors in 1915, the influence of teachers in university management has been strengthened. The management of faculties and departments has become more democratic. The heads of faculties and departments are changed regularly, and all faculty members have equal voting rights and decisionmaking rights. Meanwhile, university professors' associations have the following rights: to set the standards for issuing graduation certificates and degrees, to add or delete courses, and to hire teachers [6]. Since then, the American research university movement has flourished, and academic management has become more complex. The status of the group of teachers 


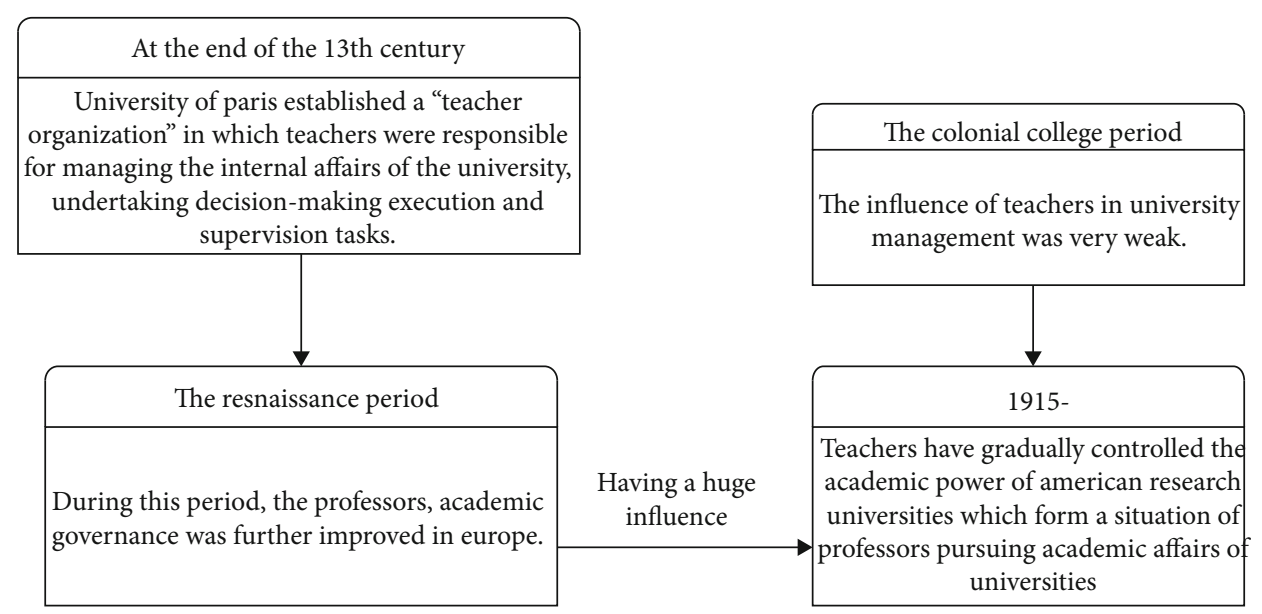

FIGURE 3: History and development of "professors' academic governance" in American research universities.

represented by professors has been elevated, and professors' authority has been prominent. Teachers have gradually controlled the academic power of admissions, student education, curriculum settings, and teacher appointments, forming a situation of professors pursuing universities' academic affairs. The overall history development of "professors' academic governance" is shown in Figure 3.

\section{Results: The Application of Artificial Intelligence Techniques in Operating Mode of Professors' Academic Governance in American Research Universities}

5.1. Clear Division of Power and Responsibility Based on the Artificial Intelligence Decision System. American research university professors and administrators generally have a relatively clear division of power and responsibility to reduce contradictions and conflicts caused by the unclear division of power. Senior administrators in American research universities are mainly responsible for university affairs, such as formulating and implementing the university's developing strategic plans, resource allocation, and campus construction. At the same time, professors are mainly responsible for academic affairs and teacher status. Professors in American research universities have the primary authority and responsibility in the academic affairs of the university. For example, according to the Bylaws of University of Michigan, the main responsibility of university professors is to manage the academic affairs of school through the academic council, such as curriculum settings [7]. Besides, "professors' academic governance" also includes participating in the decision-making process of academicrelated administrative affairs and providing advice and professional consultation for these matters. For example, MIT faculty organize regular meetings for teachers to discuss and offer advice of the academic and educational matters of the university [8]. Although professors and administrators in American research universities generally have a clear division of power, it is still difficult to distinguish which belong to the traditional academic power of professors and which belong to administrative power in many fields, especially in terms of financial budget and resource allocation [9]. Although these matters' final decision-making power generally belongs to the administrative department, professors in American research universities still have the right to make suggestions in the decision-making process. And this is also an important part of the "professors' academic governance." For example, there is a dean's Faculty Resource Committee in FAS of Harvard University with 22 professors and 5 administrative staff (shown in Table 1). Its main responsibility is to provide the college with opinions on finances and budgets [10]. And the Academic Achievement and Petitions Committee in College of Agriculture and Life Sciences of Cornell University is composed of 6 professors and three staff with the responsibility of making rules and decisions on students' petitions [11]. Although the situation of each university is different, American research universities generally involve professors or professional committees composed of professors when making plans to provide suggestions for decision-making. Some administrators might be members of the academic senate of American research universities, but they seldom play the decisive role when the academic senate members discuss academic affairs. And the professors rarely need to negotiate the final decision with senior administrators when discussing the academic affairs of universities. Meanwhile, some American research universities set up artificial intelligence decision systems. The artificial intelligence decision system is one of the important applications of artificial intelligence. It is the combination of artificial intelligence and decision support systems. And the application of expert systems enables the decision support system to apply human knowledge and help professors solve complex decision-making problems through logical reasoning. Professors could perform their duties through the artificial intelligence decision-making system.

5.2. Good Communication Platform Based on Artificial Intelligence Environment. American research universities also provide multilevel places and channels for communication and exchanges between professors and staff in terms of operating mode. For example, the president of the 
TABLE 1: Composition of a dean's faculty resource committee in FAS of Harvard University.

\begin{tabular}{lcc}
\hline & Professor & Administrative staff \\
\hline $\begin{array}{l}\text { Number of members } \\
\text { Total }\end{array}$ & 22 & 5 \\
\hline
\end{tabular}

University of California, Berkeley, and the academic senate deal with the internal affairs of the university through the establishment of a consultation and communication platform. The president of the main school, the president of the branch school, and the academic senate consult the education and scientific research policies of the university and put forward suggestions on the academic plan of the university and the branch school to the board of trustees. The president must negotiate with the academic senate when making decisions and submit them to the board of trustees for review. Also, an independent consulting and suggestion organization shall be set up to facilitate teachers and students to participate in the decision-making [12]. Good communication between the principal and the academic senate is carried out with the help of the communication platform, where school leaders and teachers can communicate and negotiate on topics of common concern, share views, exchange opinions, and avoid conflicts [13]. Also, the academic committees of faculties and departments and various committees are the main channels for communication between professors, administrators, and the board of trustees of the university. The head of the department also establishes a connection of communication between professors and administrative staff, reflecting the professor's information and suggestions to the universities and feeding back the administrative opinions to the professors, which contributes to resolving conflicts and promoting the development of "professors' academic governance." Some American research universities take advantages of pervasive computing technology to achieve the integration of physical space and virtual space and establish a communication platform based on artificial intelligence technology as an intelligent engine that supports diversified intelligent perception capabilities and service capabilities. Professors could exchange views on academic affairs with universities through the artificial intelligence platform.

5.3. The Ideology of Mutual Respect Based on the Artificial Intelligence Management and Service System. Mutual respect is the core ideology of American research universities' organizational culture, including respecting each other's authority and different opinions. Administrators need to respect the autonomy of professors in academic affairs. For example, the highest academic governance decision-making organization at MIT is the faculty, which is responsible for setting academic standards, evaluating course quality, and handling academic affairs. The president is only responsible for presiding over the faculty meeting without the power to make academic decisions. Also, professors need to respect the administrators' expertise in administration and decision-making power, reducing resistance and conflict between professors and administrative organizations. Some American research universities have established intelligent management and service methods through the col- lection and analysis of big data. The collaboration between managers and artificial intelligence can provide insight into the nature and development trends of problems in the operation of the education system, achieve more efficient resource allocation, and effectively improve universities' management and service quality which makes contributions to respecting the rights of professors.

5.4. Diversified Guarantee System Based on the Artificial Intelligence Evaluation System. 'Professors' academic governance" in an American research university not only has a relatively complete operating mechanism but also has a systematic and diverse guarantee system, including relevant laws, policies, and the guarantee of the democratic system of departments or organizations. These mechanisms constitute a complete system that effectively protects American university professors' academic power from various levels and different perspectives. From a legal perspective, the university charter and the laws of each state in America give professors the basic power for "professors' academic governance." Also, the American research universities' academic governance rules the scope of power, specific procedures, and participation channels for professors to deal with academic affairs. From the organizational perspective, the American research university academic council is the highest authority organization to exercise academic power on behalf of professors. The academic council has the function of making recommendations to the universities on academic-related administrative affairs. The power of the council is mainly concentrated on academic policies to protect the fundamental interests of the professors. Besides, the council leaders are also responsible for communicating, coordinating, and cooperating with senior administrators on important matters of universities and making a connection among professors, the administrative department, and the university board. Also, professors' associations in each college and department carry out the processing of academic affairs through the regular meeting system. For example, the College Council of Chicago University meets monthly to deal with academic affairs [14]. The Department of Education Policy and Leadership of SMU University holds a faculty meeting every two weeks to discuss the related academic matters [15]. The Department of American Studies of Brown University usually meets at least once every semester and normally once a month to discuss and vote for academic affairs [16]. Meanwhile, some American research universities have established artificial intelligence evaluation systems to guarantee the professors' rights. On the one hand, the artificial intelligence evaluation system can adopt diversified evaluation indicators according to the situation; on the other hand, it can replace manual activities in the evaluation link with repetitive activities. And the universities could make targeted corrections and improvements based on the feedback in the artificial intelligence evaluation system to ensure the implementation of the professor's academic right mechanism.

\section{Discussion}

First of all, completing the legal system for "professors' academic governance" based on the artificial intelligence 
decision-making system is the prerequisite for promoting "professors' academic governance." Universities should further clarify the scope of professors' power and the operation mode and safeguard "professors' academic governance" to provide an adequate legal system for "professors' academic governance." The university charter should clarify the content of "professors' academic governance," such as decision-making and academic affair management. At the same time, universities should establish an artificial intelligence decision-making system to support professors dealing with academic affairs. Also, it is necessary to strengthen the university's internal system's construction, improve the academic organizations' procedures, avoid unnecessary interference from administrative power to academic power, and create a favorable institutional environment for professors to conduct academic power. Universities should respect and strengthen professors' academic power, support academic organizations to independently manage academic affairs by laws and regulations, reduce administrative power's interference in academic affairs, and strengthen the role of academic staff and academic management institutions in academic affairs and university development. In addition, universities should standardize the democratic consultation mechanism based on an artificial intelligence decision-making system for professors to conduct academic governance. The democratic consultation mechanism is a necessary part of the "professors' academic governance" mechanism. Without the democratic consultation mechanism, the professors' academic power may deviate from the objective requirements of academic development. Thus, academic management institutions at all levels must set up a set of laws and regulations for "professors' academic governance" based on an artificial intelligence decision-making system to ensure the right of professors to exercise academic power.

Second, creating a good communication atmosphere for "professors' academic governance" based on artificial intelligence environment is of great significance for universities to realize "professors' academic governance." Professors need a harmonious, relaxed, and democratic communication environment. Universities should actively promote an atmosphere of equality for academics, take advantages of pervasive computing technology to achieve the integration of physical space and virtual space, establish a communication platform based on artificial intelligence technology, and fully protect the right of professors to communicate and debate freely.

Third, optimizing the organizational form of "professors' academic governance" based on an artificial intelligence evaluation system is the core of promoting university "professors' academic governance." The professor committee could set up a special committee responsible for the deliberation, consultation, and decision-making of special academic affairs, while the professor committee is only responsible for the deliberation, consultation, and decision-making of comprehensive academic affairs and the arbitration of academic affairs. Professors could evaluate the organizational form based on the artificial intelligence evaluation, and the universities could make targeted corrections and improvements based on the feedback in the evaluation system. In addition, universities should set up professor committees in each department to expand the academic power of academic staff to participate in the management and decision-making of academic affairs and promote academic democracy. Also, universities should improve the operating mechanism of the professor committee, including the improvement of the rules of the decision-making process and the academic supervision system, to ensure the standardization, democracy, and fairness of "professors' academic governance."

\section{Conclusion}

This paper studied the application of artificial intelligence techniques in the operating mode of "professors' academic governance" of American research universities based on Internet data mining, survey method, historical analysis method, and documentary method. By studying the definition, history, and development and mode of operation of "professors' academic governance" in American research universities, the results indicate that there are several characteristics of the application of artificial intelligence techniques in the mechanism of "professors' academic governance" in American research universities. First of all, American research university professors have full academic autonomy which is rarely subject to administrative intervention. There is a clear division of power and responsibility between the professors and administrators in American research universities. Some American research universities set up artificial intelligence decision systems to help professors solve complex decision-making problems through logical reasoning. Professors could perform their duties through the artificial intelligence decision-making system. Also, there are several good communication platforms for professors to discuss their opinions on academic affairs. Some American research universities take advantages of pervasive computing technology and establish a communication platform based on artificial intelligence technology which helps professors exchange views on academic affairs with universities through the artificial intelligence platform. Meanwhile, professors of American research universities exercise their academic power under the guarantee of relative laws and regulations and diversified guaranteed systems based on artificial intelligence evaluation systems to ensure the implementation of their academic rights. Furthermore, some American research universities have established an intelligent management and service system to provide insight into the nature and development trends of problems in the operation of the education system, achieve more efficient resource allocation, and effectively improve universities' management and service quality which makes contributions to respecting the rights of professors. Thereby, in order to promote the development of "professors' academic governance," universities need to clarify and protect the academic power of professors from the legal and institutional levels based on an artificial intelligence decision-making system. Furthermore, universities need to improve the framework system for "professors' academic governance," such as establishing and popularizing professor committees at universities, colleges, and departments and setting up various academic committees, and set up an 
artificial intelligence evaluation system so that professors could exercise academic power on behalf of the teachers and participate in the critical decision-making process of universities. What is more, universities should focus on cultivating and promoting an organizational culture of mutual respect and trust, communication and cooperation, and freedom and responsibility based on an artificial intelligence management and service system. Fourth, the university should establish a clear division of power and good communication platforms based on artificial intelligence environment.

\section{Data Availability}

The data used to support the findings of this study are available from the corresponding author request.

\section{Conflicts of Interest}

The authors declare no conflicts of interest.

\section{Authors' Contributions}

Wanbing Shi and Xin Li contributed equally to this work. They are co-corresponding authors of this work.

\section{Acknowledgments}

This work was supported by "the Fundamental Research Funds for the Central Universities" from Northeastern University (Research project on STEEM of American Universities, 02030022120006).

\section{References}

[1] C. L. Gou, "School management by professors: domestic reference review and research expectation," Journal of Chongqing Technology and Business University(Social Science Edition), vol. 36, no. 6, pp. 58-63, 2019.

[2] X. T. Zhang, "The connotation and implementation path of "professors' academic governance"," Jiangsu Higher Education, vol. 3, pp. 67-70, 2016.

[3] Y. Xiong and P. Guo, "Evolution, connotation and essence of professors' academic management," Research in Educational Development, vol. 21, pp. 81-84, 2012.

[4] H. Yao, J. Zhao, and H. L. He, "The connotation and essence of "professors' academic governance" in Chinese universities in the new situation," Communication of Vocational Education, vol. 17, pp. 13-15, 2015.

[5] Z. C. Pang, "Historical investigation and fundamental differences between professors' management of university's and professors' scholarly management," Modern University Education, vol. 3, pp. 61-65, 2013.

[6] C. L. Gou, "Rational speculation on university governance model: "professor governing university" and "professor governing scholarship"," Journal of National Academy of Education Administration, vol. 4, pp. 10-14, 2013.

[7] University of Michigan, "Bylaws[EB/OL]," 2021, https:// regents.umich.edu/files/meetings/01-01/ bylawsrevisedJuly2021.pdf.
[8] Massachusetts Institute of Technology, "MIT Faculty Governance[EB/OL]," 2021, http://facultygovernance.mit.edu/.

[9] H. O. Luo and Z. R. You, "The operating mechanism and organizational culture of academic governance in American higher education institutions," Journal of Higher Education, vol. 34, no. 9, pp. 95-100, 2013.

[10] Harvard University, “Advisory Committees[EB/OL]," 2021, https://www.fas.harvard.edu/advisory-committees.

[11] Cornell University, "Academic Achievement and Petitions Committee [EB/OL]," 2021, https://cals.cornell.edu/facultystaff/faculty-governance/standing-committees/academicachievement-petitions-committee.

[12] University of California, Berkeley, "Berkeley Academic Senate [EB/OL]," 2021, https://academic-senate.berkeley.edu/.

[13] Y. X. Jin and J. M. Gu, "An analysis of the effectiveness of the academic council of American research universities: take university of California, Berkeley, as an example," Tsinghua Journal of Education, vol. 3, no. 122-128, p. 139, 2020.

[14] The University of Chicago, "The College Council [EB/OL]," 2021, https://sof.uchicago.edu/the-college-council/.

[15] H. Guo and L. Liu, "How do grassroots academic organizations in American research universities implement "professor scholarship" - - a case study based on the Department of Education Policy and Leadership of SMU University," Renmin University of China Education Journal, vol. 1, pp. 73-80, 2012.

[16] Brown University, "Governance Document [EB/OL]," 2021, https://www.brown.edu/academics/american-studies/ governance-document. 